Case Study

\title{
Effects of scrambler therapy on pain and depression of patients with chronic low back pain: case study
}

\author{
Ji-Won Han, PT ${ }^{1)}$, Dong-Kyu Lee, $\left.\mathrm{PT}^{2}\right)^{*}$ \\ 1) Department of Rehabilitation Science, Graduate School, Daegu University, Republic of Korea \\ 2) Department of Physical Therapy, Sunhan Hospital: 975 Mujin-daero, Seo-gu, Gwangju 61917, \\ Republic of Korea
}

\begin{abstract}
Purpose] This study was designed to investigate the effect of scrambler therapy on the pain and depression of patients with chronic low back pain. [Subject and Methods] Applied scrambler therapy to a 52 year-old man who was diagnosed with chronic low back pain, for 40 minutes once a day during the 10-day execution. Pain and depression were measured using the visual analogue scale and the Beck Depression Inventory. [Results] According to the measurement results, pain and depression decreased after ten sessions of scramble therapy. [Conclusion] Scrambler therapy shows positive effects on pain and depression of patients with chronic low back pain.

Key words: Scrambler therapy, Low back pain, Depression
\end{abstract}

(This article was submitted Feb. 18, 2018, and was accepted Apr. 4, 2018)

\section{INTRODUCTION}

Low back pain (LBP) occurs due to stress or weakening of tendons, joints, and muscles surrounding the backbone. In particular, LBP that lasts for more than 12 weeks is considered chronic LBP ${ }^{1)}$. LBP is limited to the sacroiliac joints, hips, inguinal and femoral regions; however, it may accompany pain that radiates to the knee and even the end of the toes due to the stimulation of nerve roots ${ }^{2}$. In addition, chronic LBP is likely to cause patients to experience inconvenience in everyday life and may cause psychological problems, such as anxiety and depression, as it gets worse ${ }^{3)}$. Scrambler therapy involves the creation of artificial neuron information that is transformed into a form of an electronic wavelength that reaches the brain through electrodes attached to aching parts, thus causing nociceptors to respond ${ }^{4}$. Scrambler therapy naturally affects the analgesia signal system of A-delta and C-fibers instead of blocking the pain routes ${ }^{5)}$. Its purpose is to present a new treatment method to patients with intense pain, including chronic pain, cancer pain, and inveterate pain ${ }^{4,6)}$. Their symptoms tend to be unresponsive to and do not improve with typical treatment methods including drugs, injection therapy, and surgery6). However, scrambler therapy is not enough to confirm the pain and depression of patients with chronic LBP. This study was designed to investigate the effect of scrambler therapy on the pain and depression of patients with chronic LBP.

\section{SUBJECT AND METHODS}

This study is a single case study. The applied scrambler (GEOMC, Inc., Seoul, Korea) therapy to a 52 year-old man (weight: $169 \mathrm{~cm}$, height: $65 \mathrm{~kg}$ ) who was diagnosed with chronic LBP. He showed no abnormality in blood pressure, pulse, and breathing and had no symptoms of clouded consciousness or dysesthesia. Additionally, he read a full explanation of the study's purpose and methods, and consented to this experiment. Investigational Review Board approval is not required if one or fewer cases are reported ${ }^{7}$. The study adhered to the principles of the Declaration of Helsinki. We attached electrode-

*Corresponding author. Dong-Kyu Lee (E-mail: 1dkpt@hanmail.net)

(C2018 The Society of Physical Therapy Science. Published by IPEC Inc.

(c) (1) $\odot$ This is an open-access article distributed under the terms of the Creative Commons Attribution Non-Commercial No Derivatives

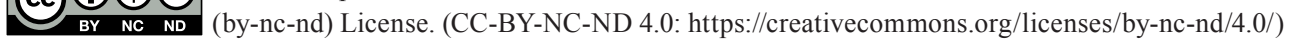


special types, whose frequency and stimulus strength were $43-52 \mathrm{~Hz}$ and $5 \mathrm{~mA}$, respectively, to deliver electronic signals naturally to the body. They were placed on areas of the body located 2-3 cm away from a source of severe pain, through 5 channels. The scrambler has a total of 16 different wave patterns of non-analgesic information. Applied the scrambler therapy for 40 minutes, once a day for 10 days $^{8)}$. Pain was measured using the visual analogue scale (VAS). The VAS is a measurement that involves a patient marking the degree of pain from 0 points to 10 points. On the VAS, 0 points equate with no pain while 10 points equate with the most severe pain. Depression was measured using Beck Depression Inventory (BDI). The BDI is a 4-point measurement method including 21 questions. Its total scores range from 0 to $63 ; 9$ points, $10-15$ points, 16-23 points, and 24-63 points equate with no depression, mild depression, depression, and serious depression, respectively.

\section{RESULTS}

The VAS score decreased from 8 to 1 after the scrambler therapy. The BDI score decreased from 22 to 7 after the scrambler therapy.

\section{DISCUSSION}

We concluded that scrambler therapy can decrease the symptoms of pain and depression in patients with chronic LBP. Scrambler therapy has been reported to decrease pain efficiently in different studies ${ }^{4,6)}$. According to the information theory, scrambler therapy recognizes a pain sensation as a piece of information, and thus artificially creates a non-analgesic signal after the scrambling to reach the brain through A-delta and C-fiber nociceptors ${ }^{6,9}{ }^{\text {. }}$. The non-analgesic signal is developed in the form of an electronic wavelength and encoded in various combinations to make the neural channel recognize it naturally ${ }^{9}$. We delivered the artificial neuron information to the nociceptor percutaneously as a wavelength signal, whose frequency and stimulus strength were $43-52 \mathrm{~Hz}$ and $5 \mathrm{~mA}$, respectively ${ }^{4}$. This study showed the therapy can reduce various types of pain, including chronic pain, inveterate pain, cancer pain, and neuropathic pain by recovering normal neuroregulation functions autonomously in the brain ${ }^{4,6,9,10)}$. Existing pain treatments, including drugs, injection therapy, and surgery, block pain sensations in the pathway where any pain sensation is delivered from the central nervous system to the brain in order to stimulate A-beta nerves, and thus cause the brain to recognize less pain ${ }^{9,10)}$. However, scrambler therapy can exert its own non-analgesic signaling system on the pain pathway, rather than blocking the pathway ${ }^{10}$. Additionally, it has been reported to decrease the symptoms of pain or depression in different studies ${ }^{11)}$. In summary, we conclude that scrambler therapy has a positive effect on decreasing pain and depression in patients with chronic LBP. The limitation of this study is that its results are difficult to generalize due to its small sample size. Furthermore, we were unable to carry out a follow-up study to investigate the post-treatment effect of scrambler therapy. Therefore, long-term research needs to be executed with a follow-up study involving more patients with chronic LBP so that the results of this study can be generalized.

\section{Conflict of interest \\ None.}

\section{REFERENCES}

1) Haldeman S: North American Spine Society: failure of the pathology model to predict back pain. Spine, 1990, 15: 718-724. [Medline] [CrossRef]

2) Wheeler AH: Diagnosis and management of low back pain and sciatica. Am Fam Physician, 1995, 52: 1333-1341, 1347-1348. [Medline]

3) Gatchel RJ, Bernstein D, Stowell AW, et al.: Psychosocial differences between high-risk acute vs. chronic low back pain patients. Pain Pract, 2008, 8: 91-97. [Medline] [CrossRef]

4) Mordarski S, Lysenko L, Gerber H, et al.: The effect of treatment with fentanyl patches on pain relief and improvement in overall daily functioning in patients with postherpetic neuralgia. J Physiol Pharmacol, 2009, 60: 31-35. [Medline]

5) Smith TJ, Coyne PJ, Parker GL, et al.: Pilot trial of a patient-specific cutaneous electrostimulation device (MC5-A Calmare ${ }^{\circledR}$ ) for chemotherapy-induced peripheral neuropathy. J Pain Symptom Manage, 2010, 40: 883-891. [Medline] [CrossRef]

6) Iseki M, Morita Y, Nakamura Y, et al.: Efficacy of limited-duration spinal cord stimulation for subacute postherpetic neuralgia. Ann Acad Med Singapore, 2009, 38: 1004-1006. [Medline]

7) Smith T, Cheville AL, Loprinzi CL, et al.: Scrambler therapy for the treatment of chronic post-mastectomy pain (cPMP). Cureus, 2017, 9: e1378. [Medline]

8) Kim YN, Lee DK, Lee HJ: Effect of pain scrambler therapy on antineuralgic pain and quality of life after shingles. J Phys Ther Sci, 2017, 29 : 1113-1115. [Medline] [CrossRef]

9) Marineo G: Untreatable pain resulting from abdominal cancer: new hope from biophysics? JOP, 2003, 4: 1-10. [Medline]

10) Sabato AF, Marineo G, Gatti A: Scrambler therapy. Minerva Anestesiol, 2005, 71: 479-482. [Medline]

11) Aceves-González C, Prado-Leon LR: Low back pain and depression: a study in a population of Mexican workers. Work, 2008, 31: 159-166. [Medline] 